\title{
Predators in northern Germany are reservoirs for parasites of One Health concern
}

\author{
Patrick Waindok $^{1} \cdot$ Katharina Raue ${ }^{1} \cdot$ Miguel L. Grilo $^{2,3} \cdot$ Ursula Siebert $^{2} \cdot$ Christina Strube $^{1}$ (i)
}

Received: 8 October 2020 / Accepted: 27 January 2021 / Published online: 6 February 2021

(C) The Author(s) 2021

\begin{abstract}
Urbanisation and invasion of wildlife into urban areas as well as human leisure activities create diverse wildlife-domestic animalhuman interfaces, increasing the risk of (zoonotic) parasite spillover from sylvatic to domestic and synanthropic cycles. This study investigated the endo- and ectoparasite fauna, emphasising on parasites of One Health Concern, of the most common predators in northern Germany between November 2013 and January 2016. Eighty red foxes (Vulpes vulpes), 18 stone martens (Martes foina) and nine raccoon dogs (Nyctereutes procyonoides) were available for the study. Overall, 79 (73.8\%) of the examined predators $(n=107)$ harboured at least one endoparasite. The most frequently detected endoparasites in red foxes were Toxocara canis (43.8\% positive individuals), Capillaria spp. (36.3\%), Alaria alata (25.0\%), Echinococcus multilocularis (26.3\%) and Uncinaria stenocephala (25.0\%). Furthermore, Toxascaris leonina, Trichuris vulpis, Taenia ssp., Mesocestoides spp. and coccidian oocysts were observed. The endoparasite species richness in raccoon dogs was comparable to red foxes, while in stone martens, only Capillaria spp. were found. Muscle digestion for detection of Trichinella spp. and antigen testing for Giardia spp. did not show positive results. Ectoparasite analyses revealed infestations with ticks species of the genus Ixodes as well as Dermacentor reticulatus. Scabies mites were not present in digested skin samples, while Demodex spp. mites were observed by faecal flotation in one red fox. Furthermore, fleas (Archaeopsylla erinacei and Chaetopsylla globiceps) were observed in the fur of red foxes, while lice were not present in any predator species. However, infestation frequency with ectoparasites was with $19.2 \%$ generally low in available predator skins $(n=99)$. Overall, the present study showed that predators in northern Germany serve as reservoirs for parasites of One Health concern, with four of the five most frequent endoparasites being zoonotic, highlighting the need of parasite surveillance in wildlife predators in order to implement measures avoiding spillovers to domestic animals and humans.
\end{abstract}

Keywords Helminths $\cdot$ Zoonoses $\cdot$ Prevalence $\cdot$ Echinococcus spp. $\cdot$ Red fox $\cdot$ Raccoon dog

Section Editor: Domenico Otranto

Christina Strube

christina.strube@tiho-hannover.de

1 Institute for Parasitology, Centre for Infection Medicine, University of Veterinary Medicine Hannover, Bünteweg 17, 30559 Hanover, Germany

2 Institute for Terrestrial and Aquatic Wildlife Research, University of Veterinary Medicine Hannover, Hanover, Germany

3 CIISA - Centre for Interdisciplinary Research in Animal Health, Faculty of Veterinary Medicine, University of Lisbon, Lisbon, Portugal

\section{Introduction}

The past and present in central Europe is characterised by a continuous anthropogenic alterations of natural environments, comprising a progressive urbanisation as well as an increasing utilisation of natural habitats for agriculture, forestry or recreational uses (Ellis 2011). However, land conversions inevitably impact resident wildlife species communities, reducing the local biodiversity and/or alter the community composition (Magurran and Henderson 2010; McKinney 2008; Murphy and Romanuk 2014). Furthermore, the fragmentation and the destruction of natural habitats provoke an increasing contact of wildlife with domestic animals, as well as humans, entailing the risk of pathogen spillovers from sylvatic to domestic or synanthropic cycles (Duscher et al. 2015; Hassell et al. 2017). Thus, parasitic diseases of wildlife are of rising 
One Health concern. Predators, like red foxes (Vulpes vulpes), play an important role in transmitting parasites to domestic and synanthropic cycles as. Further common predators at the wildlife-domestic animal-human interface in central Europe are stone martens (Martes foina) and raccoon dogs (Nyctereutes procyonoides), the latter being one of the most successful invasive carnivores in Europe (Kauhala and Kowalczyk 2011). The emergence of this invading species in northern Germany is illustrated by hunting rates reported by the ministry of the northern German federal state SchleswigHolstein (Ministry of Energy, Agriculture, the Environment, Nature and Digitalization, abbreviated as MELUND). While the number of hunted foxes and stone martens remained constant since the 1990s, the number of raccoon dogs increased almost exponential since 2004 (MELUND 2019). As in red foxes, the opportunistic feeding habits of raccoon dogs with insects, plants, and small mammals as main food source favours the transmission of parasites, and the presence of various zoonotic parasite species has been documented in both predators, including Echinococcus multilocularis, Trichinella spp. or Toxocara canis (Bruzinskaite-Schmidhalter et al. 2012; Drygala et al. 2013; Ivanov and Semenova 2000; Kornyushin and Malega 2011; Sato et al. 1999; Shimalov and Shimalov 2002; Sutor et al. 2010). Humans can be infected with E. multilocularis by accidental ingestion of infective eggs through handling of infected definitive hosts or by oral uptake of contaminated food, water or soil (Deplazes et al. 2011), causing alveolar echinococcosis (AE), a generally fatal disease if left untreated (Brunetti et al. 2010; Pawlowski et al. 2001). Furthermore, humans act as paratenic hosts after accidental ingestion of infective $T$. canis stages, and resulting toxocarosis can have detrimental impacts on health and well-being, ranging from abdominal pain, meningitis and cognitive disorders to irreversible blindness (Auer and Walochnik 2020). Besides endoparasites, native predator species are hosts for a broad range of ectoparasites including ticks and fleas, which play a major role as vectors of various pathogens. In addition, the highly contagious mite Sarcoptes scabiei may occur on endemic predator species, particularly red foxes (Soulsbury et al. 2007). The direct as well as indirect contact with infested predators can result in sarcoptic mange of dogs and pseudoscabies in humans (Birk et al. 1999).

Considering the increasing wildlife-domestic animal-human interface, surveillance of parasitic diseases in wildlife plays a crucial role to estimate the potential impact on the concept of One Health. Besides appropriate information of and control measures for humans, knowledge of the parasite fauna in predators provides important information for veterinarians to choose appropriate diagnostic techniques as well as prophylactic and therapeutic strategies to protect domestic animals and their owners from parasitic diseases and break transmission circles. Thus, the aim of the presented study was to investigate the endo- and ectoparasite fauna in the most common terrestrial predators in northern Germany, emphasising on parasites of One Health concern.

\section{Materials and methods}

\section{Study animals}

Examined predators originated mainly from the northern German federal state Schleswig-Holstein (Fig. 1). Sampling locations comprised the districts of Ostholstein, Pinneberg, Rendsburg-Eckernförde, Dithmarschen and North Frisia; including popular tourist destinations like the islands of Sylt and Amrum and the peninsula of Eiderstedt. One specimen originated from the Free and Hanseatic city of Hamburg. The predators were collected from November 2013 to January 2016 and were either shot during legal hunts, found dead or trapped during a project funded by the German Hunting Association (Deutscher Jagdverband) for accreditation of current trapping methods. Trapped animals were anaesthetised by intramuscular injection of $0.05 \mathrm{mg}$ (foxes) or $0.1 \mathrm{mg}$ (stone martens) $/ \mathrm{kg}$ bodyweight medetomidine hydrochloride $\left(\right.$ Cepetor ${ }^{\circledR}, \mathrm{CP}-$ Pharma, Germany) in combination with $10 \mathrm{mg} / \mathrm{kg}$ bodyweight ketamine (Ketamin® $100 \mathrm{mg} / \mathrm{ml}$, CP-Pharma, Germany). For euthanasia, the medicinal product T61 ${ }^{\circledR}$ (MSD, Germany) was injected intracardially, containing a combination of embutramide ( $300 \mathrm{mg} / \mathrm{kg}$ bodyweight), mebezonium iodide (75 mg/kg bodyweight) and tetracaine hydrochloride (7.5 $\mathrm{mg} / \mathrm{kg}$ bodyweight). Raccoon dogs were either shot during legal hunts or found dead.

According to $\mathrm{WHO}$ guidelines, carcasses were frozen at $-80^{\circ} \mathrm{C}$ for at least one week before further processing to prevent potential transmission of zoonotic agents, especially E. multilocularis (WHO 1984). After thawing carcasses at $4^{\circ} \mathrm{C}$, the skin with fur, sections of the intestine and different muscle parts were collected for subsequent parasitological examinations.

\section{Screening for faecal egg excretion and intestinal parasites}

Faecal samples obtained from the distal colon were analysed for parasite eggs and oocysts by the combined sedimentationflotation technique with $\mathrm{ZnSO}_{4}$ (specific gravity 1.3) as flotation medium according to Becker et al. (2016). Additionally, faecal samples were tested for Giardia spp. by a commercially available antigen-ELISA (SNAP® Giardia Test, Idexx GmbH).

For determination of adult intestinal parasites, the collected parts of the small and large intestine were opened and the intestinal content was washed through a sieve (mesh size $100 \mu \mathrm{m}$ ) with tap water. The sieve contents were flushed back into a tray and all parasites microscopically 


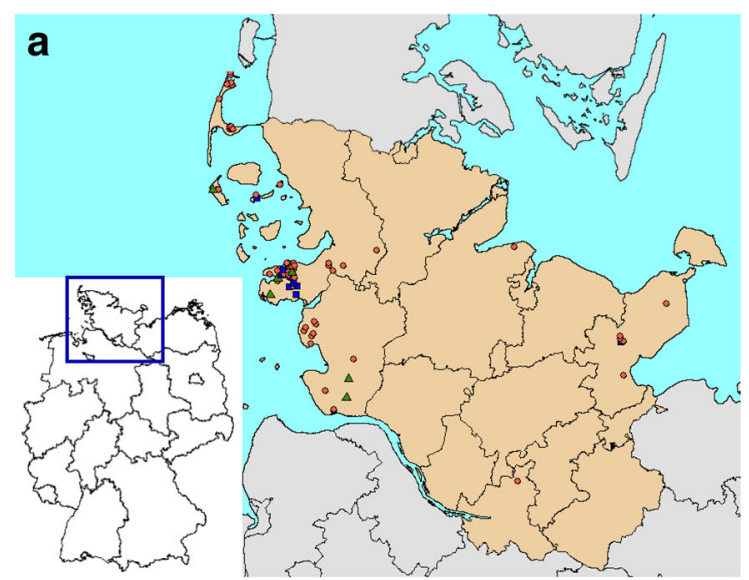

Fig. 1 a Predator sampling sites in northern Germany. Sampling sites are indicated as follows: red dots, red foxes; blue squares, stone martens; green triangles, raccoon dogs. Origin of eight animals is unknown. The

visible at $\times 10$ magnification were collected. Furthermore, the intestinal scraping technique was conducted as described by Eckert et al. (2001) to obtain Echinococcus spp. and other small helminths. Collected adult parasites and proglottids were identified morphologically to genus/ species level based on morphological keys (Macy and Berntzen 1971).

\section{Screening for Trichinella spp. muscle larvae}

Predators were analysed for Trichinella spp. muscle larvae using pepsin digestion. As the examinations started in 2013, the Commission Regulation (EC) No 2075/2005 (European Commission 2005) was adopted with modifications. Briefly, at least $50 \mathrm{~g}$ of tissue derived from skeletal muscles (tongue, masseter, diaphragm and forelimb muscles; approx. $10 \mathrm{~g}$ each) were digested in $250 \mathrm{ml}$ of a solution containing 1:100 diluted $\mathrm{HCl}(37 \% \mathrm{HCl}$; Carl Roth $\mathrm{GmbH}$, Germany) and $1 \%$ pepsin (Merck, Germany) while stirring at $37{ }^{\circ} \mathrm{C}$ until meat particles dissolved (approximately $45 \mathrm{~min}$ ). Afterwards, the solution was centrifuged at $1500 \mathrm{~g}$ for $5 \mathrm{~min}$. The supernatant was discarded and the pellet resolved in tap water and microscopically examined at 40-100 times magnification for the presence of Trichinella spp. larvae.

\section{Screening for ectoparasites}

The whole skin and fur of each specimen was macroscopically examined for the presence of ticks, fleas and lice. In addition, the transport plastic bags were checked for ectoparasites detached during transport or storage. Collected parasites were fixed in 5\% formalin (Carl Roth GmbH, Germany) and identified morphologically (Peus 1938; Babos 1964) by microscopical examination.

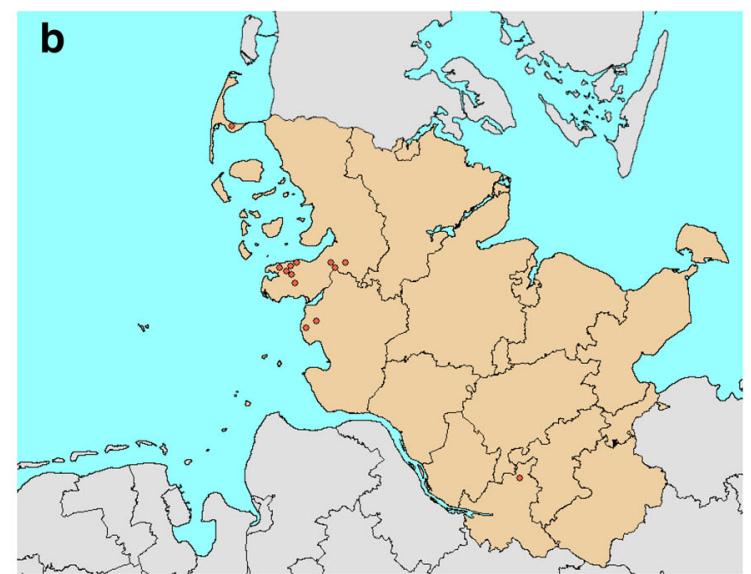

map insert pictures Germany. b Detected Echinococcus multilocularispositive red foxes

Analyses for sarcoptic mites were performed using skin digestion methodology. A piece of skin (approx. 1 $\times 1 \mathrm{~cm}$ ) from the predator's head was placed in a $15-\mathrm{ml}$ tube and digested with $5-\mathrm{ml} 10 \%$ potassium hydroxide (Carl Roth $\mathrm{GmbH}$, Germany) at $37^{\circ} \mathrm{C}$ for $60 \mathrm{~min}$. Samples were centrifuged at $1500 \mathrm{~g}$ for $10 \mathrm{~min}$ and supernatants were discarded. The pellets were suspended in 5$\mathrm{ml} 50 \%$ glucose solution, centrifuged again at $1500 \mathrm{~g}$ for $10 \mathrm{~min}$ and the floats at the surface were transferred to glass slides for microscopical examination at 50-100 times magnification.

\section{Results}

\section{Parasites detected in the intestine and/or faeces}

A total of 107 predators were made available for the analyses, the majority being red foxes ( $n=80$; sex: 35 males, 45 females; age: 16 juveniles [deciduous teeth], 60 adults [permanent teeth], 4 unknown), while only 18 stone martens (sex: 7 males, 11 females; age: 3 juveniles, 15 adults) and 9 raccoon dogs (sex: 4 males, 5 females; age: 2 juveniles, 7 adults) were provided. Overall, $79(73.8 \%)$ analysed predators harboured at least one endoparasite. Regarding predator species, 66 $(82.5 \%)$ red foxes, $6(33.3 \%)$ stone martens and 7 (77.8\%) raccoon dogs harboured endoparasites. The endoparasite fauna of the examined predators consisted of at least 9 different species, bearing the potential of greater species richness as detected ancylostomatid, Capillaria (Fig. 2a) and taeniid (Fig. 2b) eggs as well as Taenia and Mesocestoides proglottids, could not be reliably morphologically discriminated to genus and/or species level. Red foxes harboured all of the aforementioned species, while in stone martens only eggs of Capillaria spp. were found. As Capillaria 
Fig. 2 Most frequently detected endoparasites in northern German predators. Eggs of (a) Capillaria spp. and (b) Taeniidae detected in faecal samples; adults of (c)

Toxocara canis, (d)

Echinococcus multilocularis and (e) Alaria alata detected in the intestines
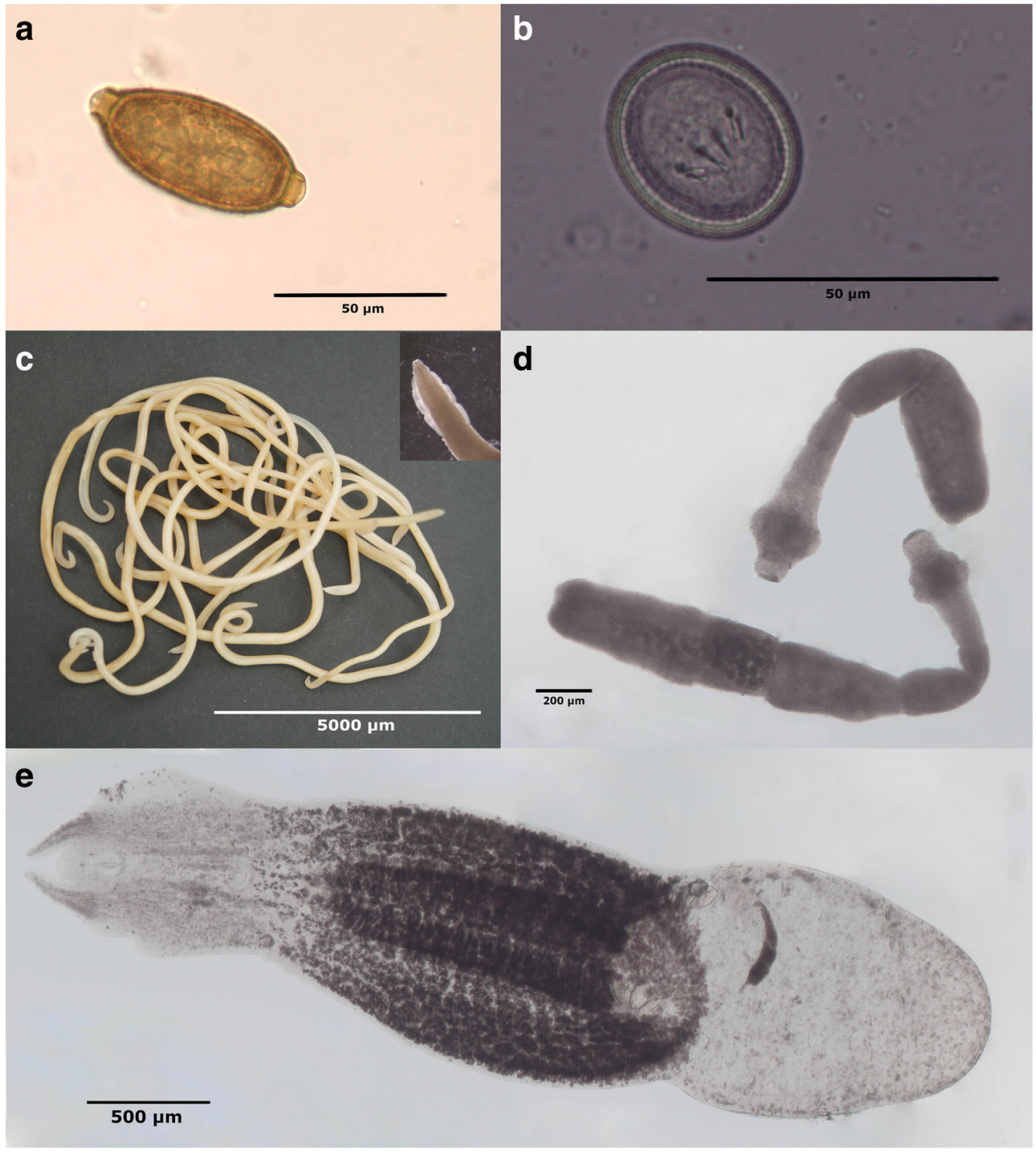

positivity was based mainly on faecal egg detection in almost all predators, morphological assignment to species level was omitted. Notably, at least seven different endoparasite species occurred in raccoon dogs, although only nine individuals were available for the examination.

The roundworm $T$. canis (Fig. 2c) was the most frequently identified helminth in red foxes (43.8\% positive specimens), followed by Capillaria spp. (36.3\%) and E. multilocularis (Fig. 2d) and Alaria alata (Figure 2e; $25.0 \%$ each). In raccoon dogs, the trematode $A$. alata was the most common helminth $(44.4 \%$ positive specimens), followed by $T$. canis $(33.3 \%)$ and taeniid infections $(22.2 \%)$. As the latter were determined by faecal egg detection, morphological genus differentiation was not possible. Further detected helminths in examined predators were hookworms, Toxascaris leonina, Trichuris vulpis and Mesocestoides species. Regarding protozoans, coproscopic analysis revealed the excretion of coccidian oocysts in 11
(13.8\%) predators, while antigen testing for Giardia spp. remained negative. Detailed data on observed endoparasites and frequencies are listed in Table 1.

\section{Co-infections with endoparasites}

In $30(38.0 \%)$ of the 79 endoparasite positive predators, a mono-infection was determined, while 49 (62.0\%) were co-infected with up to six differentiable parasite genera or species, respectively (Fig. 3). Of the positive red foxes, $21(31.8 \%)$ were single infected, while multiple genera/ species occurred in $45(68.2 \%)$ of positive individuals. A co-infection with two genera/species was detected in 10 $(15.2 \%)$, tri-infections in $18(27.3 \%)$, tetra-infections in 7 $(10.6 \%)$, penta-infections in $6(9.1 \%)$ and hexa-infections in $4(6.1 \%)$ of the endoparasite positive red foxes. The observed co-infections consisted of different combinations including the most frequently detected 
Table 1 Endoparasite frequency in terrestrial predators in northern Germany

\begin{tabular}{|c|c|c|c|c|c|c|c|c|}
\hline & \multicolumn{2}{|c|}{$\begin{array}{l}\text { Red fox } \\
(n=80)\end{array}$} & \multicolumn{2}{|c|}{$\begin{array}{l}\text { Stone marten } \\
(n=18)\end{array}$} & \multicolumn{2}{|c|}{$\begin{array}{l}\text { Raccoon dog } \\
(n=9)\end{array}$} & \multicolumn{2}{|c|}{$\begin{array}{l}\text { All predators } \\
(n=107)\end{array}$} \\
\hline & No. & $\%$ & No. & $\%$ & No. & $\%$ & No. & $\%$ \\
\hline Endoparasite positive & 66 & $82.5 \%$ & 6 & $33.3 \%$ & 7 & $77.8 \%$ & 79 & $73.8 \%$ \\
\hline Endoparasite negative & 14 & $17.5 \%$ & 12 & $66.7 \%$ & 2 & $22.2 \%$ & 28 & $26.2 \%$ \\
\hline \multicolumn{9}{|l|}{ Trematoda } \\
\hline Alaria alata (eggs and/or adults) & 20 & $25.0 \%$ & 0 & $0.0 \%$ & 4 & $44.4 \%$ & 24 & $22.4 \%$ \\
\hline \multicolumn{9}{|l|}{ Cestodea } \\
\hline Taenia spp. (adults) & 13 & $16.3 \%$ & 0 & $0.0 \%$ & 0 & $0.0 \%$ & 13 & $12.1 \%$ \\
\hline Echinococcus multilocularis (adults) & 21 & $26.3 \%$ & 0 & $0.0 \%$ & 0 & $0.0 \%$ & 21 & $19.6 \%$ \\
\hline Taeniidae (eggs) & 7 & $8.8 \%$ & 0 & $0.0 \%$ & 2 & $22.2 \%$ & 9 & $8.4 \%$ \\
\hline Mesocestoides spp. (adults) & 2 & $2.5 \%$ & 0 & $0.0 \%$ & 0 & $0.0 \%$ & 2 & $1.9 \%$ \\
\hline \multicolumn{9}{|l|}{ Nematoda } \\
\hline Uncinaria stenocephala (adults) & 20 & $25.0 \%$ & 0 & $0.0 \%$ & 1 & $11.1 \%$ & 21 & $19.6 \%$ \\
\hline Ancylostomatidae (eggs) & 1 & $1.3 \%$ & 0 & $0.0 \%$ & 1 & $11.1 \%$ & 2 & $1.9 \%$ \\
\hline Toxocara canis (eggs and/or adults) & 35 & $43.8 \%$ & 0 & $0.0 \%$ & 3 & $33.3 \%$ & 38 & $35.5 \%$ \\
\hline Toxascaris leonina (eggs and/or adults) & 8 & $10.0 \%$ & 0 & $0.0 \%$ & 1 & $11.1 \%$ & 9 & $8.4 \%$ \\
\hline Ascarids (preadult) & 1 & $1.3 \%$ & 0 & $0.0 \%$ & 0 & $0.0 \%$ & 1 & $0.9 \%$ \\
\hline $\begin{array}{l}\text { Capillaria spp. (mostly eggs, very rarely } \\
\text { adults) }\end{array}$ & 29 & $36.3 \%$ & 3 & $33.3 \%$ & 1 & $11.1 \%$ & 36 & $33.6 \%$ \\
\hline Trichuris vulpis (eggs and/or adults) & 8 & $10.0 \%$ & 0 & $0.0 \%$ & 0 & $0.0 \%$ & 8 & $7.5 \%$ \\
\hline Trichinella spp. (muscle larvae) & 0 & $0.0 \%$ & 0 & $0.0 \%$ & 0 & $0.0 \%$ & 0 & $0.0 \%$ \\
\hline \multicolumn{9}{|l|}{ Trepomonadea } \\
\hline Giardia spp. & 0 & $0.0 \%$ & 0 & $0.0 \%$ & 0 & $0.0 \%$ & 0 & $0.0 \%$ \\
\hline \multicolumn{9}{|l|}{ Coccidia } \\
\hline Oocysts & 11 & $13.8 \%$ & 0 & $0.0 \%$ & 1 & $11.1 \%$ & 12 & $11.2 \%$ \\
\hline
\end{tabular}

endoparasites; however, no distinct distribution pattern could be assessed.

In raccoon dogs, three (42.9\%) of the endoparasitic positive specimens were mono-infected, while four $(57.1 \%)$ individuals showed co-infections. Of these, two endoparasite genera/species occurred in one $(14.3 \%)$ and a triinfection in three $(42.9 \%)$ positive raccoon dogs. Similar to red foxes, the most frequently detected endoparasites contributed to the co-infections, but no combination occurred repeatedly.

Fig. 3 Endoparasite co-infections in northern German predators.
No co-infection with different endoparasite genera was determined in stone martens as Capillaria spp. were the only observed endoparasites in this predator species.

\section{Screening for Trichinella spp. muscle larvae}

None of the 100 predators available for Trichinella examination ( 77 red foxes, 18 stone martens and 5 raccoon dogs) showed larvae after artificial muscle digestion, although parts

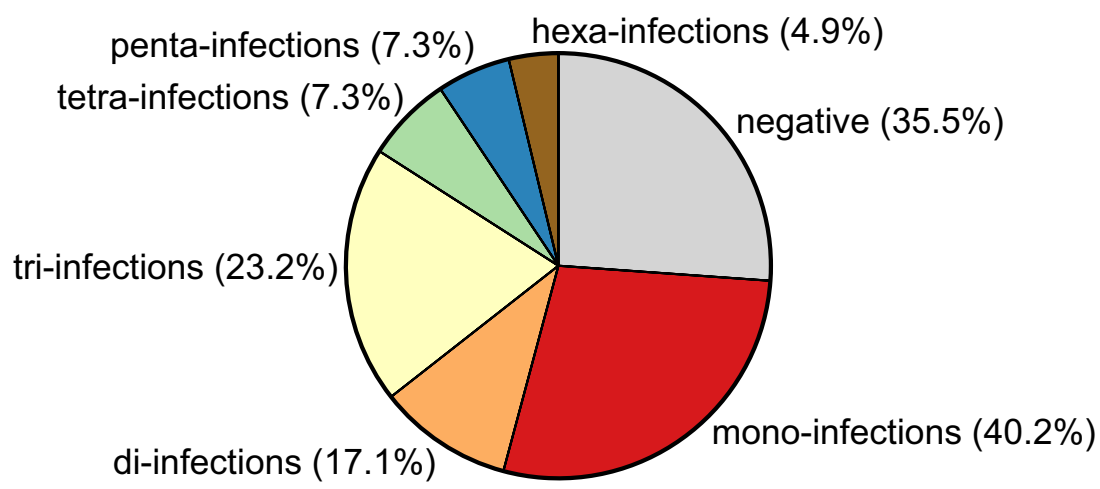


of different muscles were digested to enhance detection of potential infections.

\section{Infestations with ectoparasites}

From 99 predators (76 red foxes, 18 stone martens and 5 raccoon dogs), the skin with fur was available for ectoparasite analyses. Of these, 19 (19.2\%) were infested, and seven different ectoparasite taxa were identified. On predator species level, $12(15.8 \%)$ red foxes and 7 (38.9\%) stone martens were infested, while no ectoparasites were detected on the five available raccoon dog skins. Ticks of the genus Ixodes were the most frequent ectoparasites. Both red foxes and stone martens harboured Ixodes hexagonus and Ixodes canisuga. While these were the only ectoparasites detected on stone martens, the tick species Ixodes ricinus and Dermacentor reticulates were additionally recovered from one red fox. Furthermore, infestations with the flea species Archaeopsylla erinacei and Chaetopsylla globiceps were identified. Additionally, Demodex spp. mites were found in one red fox by faecal flotation. Examinations for sarcoptic mites as well as lice did not show positive results. Detailed results on the occurrence and frequency of ectoparasite infestations are summarised in Table 2.

Co-infections of different ectoparasite species were detected in red foxes only. One fox was infested with I. hexagonus and A. erinacei, and another one with I. ricinus, D. reticulatus and $A$. erinacei. The red fox identified to be faecal positive for Demodex spp. was infested with $I$. hexagonus ticks.

\section{Discussion}

Urbanisation due to increasing urban development and agricultural land use with the consequence of ecological fragmentation as well as the invasion of wildlife into urban areas and sites of people's leisure activities creates diverse wildlifedomestic animal-human interfaces. Such interfaces represent a critical point for cross-species transmission and emergence of pathogens (Hassell et al. 2017). In the light of the One Health concept, wildlife predators play an important role at these interfaces by maintaining monoxenous or heteroxenous cycles of parasites transmissible to domestic animals or humans. Here, we aimed to identify the parasite fauna in northern German wildlife predators emphasising on parasites of One Health concern. Most predators available for this study were red foxes, which harboured at least nine different endoparasites, reflecting the species diversity recorded in other European countries (Al-Sabi et al. 2013; Borgsteede 1984; Bruzinskaite-Schmidhalter et al. 2012; Criado-Fornelio et al. 2000; Lledo et al. 2015; Smith et al. 2003). Notably, four of the five most frequent endoparasites detected in red foxes are of zoonotic concern.

One of the most important parasitic zoonoses is caused by E. multilocularis. Intensive epidemiological research on its endemicity in fox populations since the 1990s showed extensive expansion of this parasite into many European countries (Gottstein et al. 2015), whereby the number of human alveolar echinococcosis (AE) cases correlates with the local abundance of infected red foxes (Schweiger et al. 2007). In southwestern Germany, E. multilocularis is highly endemic with about $75 \%$ of red foxes being infected, and a human disease incidence of
Table 2 Ectoparasite frequency in terrestrial predators in northern Germany

\begin{tabular}{|c|c|c|c|c|c|c|c|c|}
\hline & \multicolumn{2}{|c|}{ Red fox $(n=76)$} & \multicolumn{2}{|c|}{$\begin{array}{l}\text { Stone marten } \\
(n=18)\end{array}$} & \multicolumn{2}{|c|}{$\begin{array}{l}\text { Raccoon dog } \\
(n=5)\end{array}$} & \multicolumn{2}{|c|}{$\begin{array}{l}\text { All predators } \\
(n=99)\end{array}$} \\
\hline & No. & $\%$ & No. & $\%$ & No. & $\%$ & No. & $\%$ \\
\hline Ectoparasite positive & 12 & $15.8 \%$ & 7 & $38.9 \%$ & 0 & $0.0 \%$ & 19 & $19.2 \%$ \\
\hline Ectoparasite negative & 64 & $84.2 \%$ & 11 & $61.1 \%$ & 5 & $100 \%$ & 80 & $80.8 \%$ \\
\hline \multicolumn{9}{|l|}{ Acari } \\
\hline Ixodes hexagonus & 4 & $5.3 \%$ & 6 & $33.3 \%$ & 0 & $0.0 \%$ & 10 & $10.1 \%$ \\
\hline Ixodes canisuga & 5 & $6.6 \%$ & 1 & $5.6 \%$ & 0 & $0.0 \%$ & 6 & $6.1 \%$ \\
\hline Ixodes ricinus & 1 & $1.3 \%$ & 0 & $0.0 \%$ & 0 & $0.0 \%$ & 1 & $1.0 \%$ \\
\hline Dermacentor reticulatus & 1 & $1.3 \%$ & 0 & $0.0 \%$ & 0 & $0.0 \%$ & 1 & $1.0 \%$ \\
\hline Demodex spp.* & 1 & $1.3 \%$ & 0 & $0.0 \%$ & 0 & $0.0 \%$ & 1 & $1.0 \%$ \\
\hline Sarcoptic mites & 0 & $0.0 \%$ & 0 & $0.0 \%$ & 0 & $0.0 \%$ & 0 & $0.0 \%$ \\
\hline \multicolumn{9}{|l|}{ Insecta } \\
\hline Archaeopsylla erinacei & 3 & $3.9 \%$ & 0 & $0.0 \%$ & 0 & $0.0 \%$ & 3 & $3.0 \%$ \\
\hline Chaetopsylla globiceps & 1 & $1.3 \%$ & 0 & $0.0 \%$ & 0 & $0.0 \%$ & 1 & $1.0 \%$ \\
\hline Lice & 0 & $0.0 \%$ & 0 & $0.0 \%$ & 0 & $0.0 \%$ & 0 & $0.0 \%$ \\
\hline
\end{tabular}

*Detected with the combined sedimentation-flotation method 
2.18 cases $/ 100,000$ inhabitants in the southwestern federal state of Baden-Wuerttemberg being significantly higher than in Germany as a whole with 0.64 cases/100,000 inhabitants (Schmidberger et al. 2018). However, a northward expansion has been documented in Europe, recognising E. multilocularis for the first time in 2000 in Denmark (Saeed et al. 2006) and 2011 in southern Sweden (OIE 2011). In this study, a quarter (26.3\%) of available red foxes carried adult E. multilocularis in their intestine. Previous studies on the occurrence of E. multilocularis in red foxes in the here investigated northern German region remained either negative (Manke 1997) or showed a prevalence of only $0.4 \%$ (Nebel 1996). This increase from $0.0-0.4$ to $25.3 \%$ within 20 years reveals not only newly established endemicity in the most northern part of Germany (cf. Fig. 1b), but may also affect the incidence of human disease. However, between 2001 and 2018, only five human AE cases have been reported in the study area (federal states of Schleswig-Holstein and the Free and Hanseatic city of Hamburg; RKI 2020), and it remained unclear if these infections were autochthonous. Nevertheless, it has to be kept in mind that the actual incidence may be biased since the long incubation period of human $\mathrm{AE}$ rather reflects the infection risk 10-15 years ago (Piarroux et al. 2013; Said-Ali et al. 2013; Schweiger et al. 2007). Besides red foxes, the raccoon dog has been identified as an important host for E. multilocularis (Oksanen et al. 2016), exhibiting a similar total biotic potential as red foxes (Kapel et al. 2006). Here, E. multilocularis was not found in the intestines of examined raccoon dogs; however, only nine specimens were made available for the study.

In recent years, the trematode $A$. alata has gained attention as a One Health threat due to increased findings of its mesocercariae in wild boar meat in Germany, initiating a reassessment of the potential human health risk (BfR 2007; Möhl et al. 2009; Riehn et al. 2012). While carnivores serve as definitive hosts, mesocercariae can affect a wide range of mammal paratenic hosts including humans and remain infective after transmission between paratenic hosts (Möhl et al. 2009). Here, the frequency of A. alata in examined northern German red foxes was $25 \%$. Overall, the A. alata prevalence in red foxes in northwestern Europe is wide-ranging with reported values between 17 and 95\% in Denmark, Lithuania, the Netherlands and Ireland (Al-Sabi et al. 2013; BruzinskaiteSchmidhalter et al. 2012; Franssen et al. 2014b; Murphy et al. 2012). Additionally, raccoon dogs are very suitable definitive hosts, showing prevalences of up to 68-97\% (Al-Sabi et al. 2013; Bruzinskaite-Schmidhalter et al. 2012; Laurimaa et al. 2016). High susceptibility of this predator species is confirmed by the present study, revealing A. alata as the most frequent parasite in raccoon dogs with about half of the examined specimens being infected. However, further research is necessary to estimate the impact of raccoon $\operatorname{dogs}$ on A. alata transmission cycles and related public health issues in northern Germany as only a low number of specimens were provided for this study.

Nematode meat-transmitted parasites of One Health concern are different species of the genus Trichinella. Infections of red foxes with Trichinella spp. is considered potential indicator for its occurrence in sylvatic cycles. Consequently, various prevalence studies have been conducted in this predator species (Clausen and Henriksen 1976; Enemark et al. 2000; Hurnikova and Dubinsky 2009; Zimmer et al. 2009). However, the Trichinella spp. prevalence has been continuously low in such monitorings (Chmurzynska et al. 2013; Enemark et al. 2000; Franssen et al. 2014a; Zimmer et al. 2009), which is why the absence of Trichinella spp. positivity is to be expected if, as in the present study, the number of analysed animals is rather low. Furthermore, freezing of fox carcasses to prevent potential E. multilocularis infection of the examiners may influence the detection of Trichinella larvae (Franssen et al. 2014a). Therefore, method adjustments are recommended for wildlife meat to improve efficiency (Franssen et al. 2014a).

With an infection rate of $44 \%, T$. canis, the zoonotic roundworm of canids, was the most frequent endoparasite in the examined northern German red foxes. Recent studies in countries with comparable climatic conditions report similar prevalences of 59-61\% in Denmark (Al-Sabi et al. 2013; Saeed et al. 2006), $41 \%$ in Lithuania (Bruzinskaite-Schmidhalter et al. 2012) and $61 \%$ in the Netherlands (Franssen et al. 2014b). In the northern German raccoon dogs, the T. canis frequency of $33 \%$ was lower than that in red foxes. In Denmark and Lithuania, prevalences of $13 \%$ and $18 \%$ were found (Al-Sabi et al. 2013; Bruzinskaite-Schmidhalter et al. 2012). Interestingly, the present as well as the Danish study (Al-Sabi et al. 2013) found T. canis to be more abundant in red foxes and A. alata to be more abundant in raccoon dogs. In contrast, in Lithuania only $T$. canis was more abundant in red foxes, while both predators exhibited similar high $A$. alata prevalences of 95\% (red foxes) and 97\% (raccoon dogs) (Bruzinskaite-Schmidhalter et al. 2012; Franssen et al. 2014b). Although dogs are mostly responsible for environmental contaminations with $T$. canis eggs, red foxes are also important contributors, especially in rural areas (Nijsse et al. 2015). Contaminated soil is considered the main source of human toxocarosis, one of most reported zoonotic helminth infections worldwide (Fakhri et al. 2018; Rubinsky-Elefant et al. 2010). Thus, environmental contamination is a major public health concern as human toxocarosis may cause severe organ injuries, depending on the intensity of infection, the migration behaviour of larvae and the induced immune response (Taylor et al. 1988).

Noteworthy, infections with Giardia protozoans, which may be zoonotic depending on the species or genotype, respectively, were not observed in any predator in the present study, although a highly sensitive antigen test was utilised. 
As the One Health concept considers not only zoonotic but also pathogens transmissible between wildlife and domestic animals, further endoparasites detected in the northern German predators are reason for concern, especially regarding dogs. Besides Taenia and Mesocestoides spp. tapeworms, the nematode Uncinaria stenocephala, the most common canine hookworm in cooler regions as well as Toxascaris leonina, Trichuris vulpis and Capillaria spp. were observed. As Capillaria diagnosis mostly relied on faecal egg detection, morphological species determination was omitted. Thus, it remains unclear whether the predators harboured an intestinal Capillaria putorii infection and/or airway infections with Capillaria aerophila (syn. Eucoleus aerophilus) or Capillaria boehmi (syn. Eucoleus boehmi). All of them can also infect dogs, and Capillaria boehmi has been recently reported as a treatment challenge in parasitised dogs (GillisGermitsch et al. 2020). As examined faeces was collected from the distal colon, Capillaria paranalis (syn. Pearsonema paranalis), a parasite of the anal sac first described in stone martens and recently in red foxes, can be excluded as source of the detected eggs (Forstner and Geisel 1980; Tomczuk et al. 2019). Noteworthy, Capillaria spp. were the only detected parasites in the examined stone martens. Even though this result is debatable due to low numbers of specimens made available for this study, different previous investigations report rather high Capillaria infection rates, but rather low prevelances of other endoparasitic helminths (Gorski et al. 2006; Kornas et al. 2013; Pfeiffer et al. 1989). Finally, it has to be mentioned that the Capillaria eggs in the predator's faces may not result from patent infections but may derive from hunted birds or rodents in terms of an intestinal passage. This also applies to the coccidian oocysts observed in faecal samples of red foxes $(14 \%)$ and raccoon dogs $(11 \%)$, as no histological examination of the predator's intestines was performed.

Besides being hosts for endoparasites of One Health concern, wildlife predators are commonly infested by various species of ectoparasites such as fleas, mites and ticks, and ectoparasites potentially infesting humans or domestic animals may additionally act as vectors for numerous zoonotic pathogens. Overall, ectoparasite detection in the predators was less frequent than expected as only about one fifth of the examined individuals were found to be infested. This may be attributed to active or passive detachment of the parasites during laytime or transport of the carcasses (Lledo et al. 2015), and subsequent freezing at $-80{ }^{\circ} \mathrm{C}$ may have additionally impeded ectoparasite detection. Furthermore, the rather low numbers of provided predators, especially of stone martens and raccoon dogs, is a general shortcoming of the study. Taking these issues together, the absence of specific ectoparasite species or infestations in general, as observed for raccoon dogs, needs to be interpreted with caution.
In red foxes, the most prevalent ectoparasites were I. canisuga and I. hexagonus, recorded on $7 \%$ and $5 \%$ of the specimens, respectively. Both ticks also occurred on stone martens, where infestations with I. hexagonus were predominant $(33 \%)$ compared to I. canisuga $(6 \%)$. Additionally, one red fox was infested with $I$. ricinus and $D$. reticulatus. While I. canisuga is not important regarding disease transmission, both I. ricinus and I. hexagonus are confirmed vectors for spirochetes of the Borrelia burgdorferi sensu lato complex and, as well as D. reticulatus, for tick-borne encephalitis (TBE) virus. These two pathogens represent the most important tick-borne diseases in Europe, substantially impacting Health systems (Khatchikian et al. 2015; Lohr et al. 2015; Shedrawy et al. 2018). Additionally, dogs and horses may suffer from both pathogens (Klaus et al. 2013; Pfeffer and Dobler 2011; Waldvogel et al. 1981). However, Anaplasma phagocytophilum transmitted by I. ricinus and Babesia canis transmitted by $D$. reticulatus play a more important role in domestic animals in central Europe. Overall, the infestation risk for humans and domestic animals with the two most common tick species in the predators is moderate to low as both I. hexagonus and I. canisuga are nest-dwelling ticks (EstradaPeña 2017). Nevertheless, I. ricinus infestation in humans and domestic animals and D. reticulatus infestation in dogs and horses (Drehmann et al. 2020) are common in Germany, enabling spillover of tick-borne pathogen infections in foxes and other wildlife to humans and domestic animals and thus constituting a One Health issue that should not be neglected. Moreover, predators might not only play a role in the epidemiology of vector-transmitted pathogens by being carriers and disseminator of ectoparasites, but also by serving as pathogen reservoirs, by suppressing the abundance and behaviour of dilution hosts, or, in case of mesopredators like foxes, by suppressing the abundance and behaviour of small predators feeding on rodent reservoir hosts (Haemig et al. 2008). For example, red foxes have been implicated in the spread of TBE since the numbers of red fox correlated positively with the numbers of human TBE cases (Haemig et al. 2008).

Burrowing sarcoptic mites, the etiologic agent of mange, can be transmitted from predators to domestic carnivores, especially those used for hunting, and, occasionally, humans. In this study, infestations with Sarcoptes scabiei could not be detected in the examined predators. Noteworthy, sarcoptic mange was also absent in red foxes originating from Danish Jutland, directly bordering to the northern German study region, while $45 \%$ of examined red foxes from the region of Copenhagen were infested (Al-Sabi et al. 2014). Interestingly, faecal flotation revealed the presence of Demodex spp. mites in one red fox; however, it remains unclear whether this finding resulted from an infestation of the predator or derived from preyed rodents.

Regarding ectoparasitic insects, different flea species have been reported from predatory mammals like red foxes, stone 
martens or raccoon dogs, including C. globiceps, A. erinacei and Ctenocephalides canis as well as the human flea, Pulex irritans, amongst others (Foley et al. 2017; Karbowiak et al. 2016; Kočišová et al. 2006; Vichova et al. 2018). Here, the hedgehog flea, A. erinacei, and the fox specialist $C$. globiceps were identified on red foxes, but infestation rates were low with $4 \%$ and $1 \%$, respectively. However, it needs to be mentioned that infestation rates and flea species richness in northern German predators is probably higher as fleas start to abandon dead hosts rather quickly (Hsu and Wu 2001). Similar to ticks, fleas not restricted to a certain host species may allow pathogen transmission, e.g. of Bartonella spp., from wildlife to (carnivore) domestic animals, and possibly also to humans.

\section{Conclusions}

The endo- and ectoparasite fauna in northern German predators comprises a variety of species, and many of them are of One Health concern. Despite mentioned shortcomings, the results obtained in the presented study can provide valuable information on the potential risk of parasite spillover from predators to humans and domestic animals. Generally, stone martens exhibited the lowest parasite species richness and thus seem to have minor importance in transmissions at the wildlife-domestic animal-human interface, while in the invasive raccoon dog, an endoparasite parasite fauna similar to red foxes has established. Furthermore, the study revealed that E. multilocularis is now also being endemic in the most northern part of Germany. Additionally, A. alata and T. canis were frequently detected zoonotic parasites, but also ectoparasites like ticks may contribute to transmission of pathogens. As the studied predators are widely distributed and urbanisation as well as adaption of predators to anthropogenic surroundings as rural and urban areas enhance the transmission risk to domestic animals and humans, further studies are needed to follow the One Health notion and implement successful surveillance allowing efficient risk assessment of wildlife parasite and vector-borne pathogen spillover.

Acknowledgements The authors want to thank Petra Thomas for technical assistance and the hunters, veterinarians and biologists from the ITAW for the support in this study and the Department of Pathology, University of Veterinary Medicine Hannover.

Funding Open Access funding enabled and organized by Projekt DEAL. This study was partly funded by the Ministry of Energy, Agriculture, the Environment, Nature and Digitalization of the federal state SchleswigHolstein, Germany. The animals were partly caught as part of a study funded by the German Hunting Association (Deutscher Jagdverband).

\section{Declarations}

Ethics statement Animal trapping, handling and euthanasia were performed in accordance with the German Animal Welfare act in addition to national and international guidelines for animal welfare, and were permitted by the German Schleswig-Holstein Ministry of Energy, Agriculture, the Environment, Nature and Digitalization (Ministerium für Energiewende, Landwirtschaft, Umwelt, Natur und Digitalisierung) under reference number V242-7224.121-19.

Conflict of interest The authors declare no competing interests.

Open Access This article is licensed under a Creative Commons Attribution 4.0 International License, which permits use, sharing, adaptation, distribution and reproduction in any medium or format, as long as you give appropriate credit to the original author(s) and the source, provide a link to the Creative Commons licence, and indicate if changes were made. The images or other third party material in this article are included in the article's Creative Commons licence, unless indicated otherwise in a credit line to the material. If material is not included in the article's Creative Commons licence and your intended use is not permitted by statutory regulation or exceeds the permitted use, you will need to obtain permission directly from the copyright holder. To view a copy of this licence, visit http://creativecommons.org/licenses/by/4.0/.

\section{References}

Al-Sabi MN, Chriel M, Jensen TH, Enemark HL (2013) Endoparasites of the raccoon dog (Nyctereutes procyonoides) and the red fox (Vulpes vulpes) in Denmark 2009-2012 - A comparative study. Int J Parasitol Parasites Wildl 2:144-151

Al-Sabi MN, Halasa T, Kapel CM (2014) Infections with cardiopulmonary and intestinal helminths and sarcoptic mange in red foxes from two different localities in Denmark. Acta Parasitol 59:98-107

Auer H, Walochnik J (2020) Toxocariasis and the clinical spectrum. Adv Parasitol 109:111-130

Babos S (1964) Die Zeckenfauna Mitteleuropas. Akademiai Kiado, Budapest

Becker AC, Kraemer A, Epe C, Strube C (2016) Sensitivity and efficiency of selected coproscopical methods-sedimentation, combined zinc sulfate sedimentation-flotation, and McMaster method. Parasitol Res 115:2581-2587

BfR (2007) Wildschweinfleisch kann den gefährlichen Duncker'schen Muskelegel enthalten. Stellungnahme Nr. 027/2007 des BfR vom 1. Juli 2007. Berlin

Birk RW, Tebbe B, Schein E, Zouboulis CC, Orfanos CE (1999) Pseudoscabies transmitted by red fox. Hautarzt 50:127-130

Borgsteede FH (1984) Helminth parasites of wild foxes (Vulpes vulpes L.) in The Netherlands. Z Parasitenkd 70:281-285

Brunetti E, Kern P, Vuitton DA, Writing Panel for the W-I (2010) Expert consensus for the diagnosis and treatment of cystic and alveolar echinococcosis in humans. Acta Trop 114:1-16

Bruzinskaite-Schmidhalter R, Sarkunas M, Malakauskas A, Mathis A, Torgerson PR, Deplazes P (2012) Helminths of red foxes (Vulpes vulpes) and raccoon dogs (Nyctereutes procyonoides) in Lithuania. Parasitology 139:120-127

Chmurzynska E, Rozycki M, Bilska-Zajac E, Nockler K, Mayer-Scholl A, Pozio E, Cencek T, Karamon J (2013) Trichinella nativa in red foxes (Vulpes vulpes) of Germany and Poland: Possible different origins. Vet Parasitol 198:254-257

Clausen B, Henriksen SA (1976) The prevalence of Trichinella spiralis in foxes (Vulpes vulpes) and other game species in Denmark. Nord Vet Med 28:265-270

Criado-Fornelio A, Gutierrez-Garcia L, Rodriguez-Caabeiro F, ReusGarcia E, Roldan-Soriano MA, Diaz-Sanchez MA (2000) A 
parasitological survey of wild red foxes (Vulpes vulpes) from the province of Guadalajara, Spain. Vet Parasitol 92:245-251

Deplazes P, van Knapen F, Schweiger A, Overgaauw PA (2011) Role of pet dogs and cats in the transmission of helminthic zoonoses in Europe, with a focus on echinococcosis and toxocarosis. Vet Parasitol 182:41-53

Drehmann M, Springer A, Lindau A, Fachet K, Mai S, Thoma D, Schneider C, Chitimia-Dobler L, Bröker M, Dobler G, Strube C (2020) The spatial distribution of Dermacentor ticks (Ixodidae) in Germany-evidence of a continuing spread of Dermacentor reticulatus. Front Vet Sci 7:578220

Drygala F, Werner U, Zoller H (2013) Diet composition of the invasive raccoon dog (Nyctereutes procyonoides) and the native red fox (Vulpes vulpes) in north-east Germany. Hystrix 24:190-194

Duscher GG, Leschnik M, Fuehrer H-P, Joachim A (2015) Wildlife reservoirs for vector-borne canine, feline and zoonotic infections in Austria. Int J Parasitol Parasites Wildl 4:88-96

Eckert J, Gemmell MA, Meslin FX, Pawlowski ZS, Organization WH (2001) WHO/OIE manual on echinococcosis in humans and animals: a public health problem of global concern. In. World Organisation for Animal Health and World Health Organization, Paris, p. 80.

Ellis EC (2011) Anthropogenic transformation of the terrestrial biosphere. Philos Trans A Math Phys Eng Sci 369:1010-1035

Enemark HL, Bjorn H, Henriksen SA, Nielsen B (2000) Screening for infection of Trichinella in red fox (Vulpes vulpes) in Denmark. Vet Parasitol 88:229-237

Estrada-Peña A (2017) Ticks of Europe and North Africa - a guide to species identification. Springer International Publishing AG, Cham, Switzerland

European Commission (2005) COMMISSION REGULATION (EC) No 2075/2005 of 5 December 2005 laying down specific rules on official controls for Trichinella in meat.

Fakhri Y, Gasser RB, Rostami A, Fan CK, Ghasemi SM, Javanian M, Bayani M, Armoon B, Moradi B (2018) Toxocara eggs in public places worldwide - a systematic review and meta-analysis. Environ Pollut 242:1467-1475

Foley P, Foley J, Sandor AD, Ionica AM, Matei IA, D'Amico G, Gherman CM, Dom AC, Mihalca AD (2017) Diversity of Flea (Siphonaptera) Parasites on Red Foxes (Vulpes vulpes) in Romania. J Med Entomol 54:1243-1250

Forstner MJ, Geisel O (1980) Capillaria paranalis sp. n. (Nematoda, Trichuridae), a new type of trichurid nematode from the anal sacs of the stone marten (Martes foina Erxleben, 1777). Berl Munch Tierarztl 93:312-316

Franssen F, Deksne G, Esite Z, Havelaar A, Swart A, van der Giessen J (2014a) Trend analysis of Trichinella in a red fox population from a low endemic area using a validated artificial digestion and sequential sieving technique. Vet Res 45:120-131

Franssen F, Nijsse R, Mulder J, Cremers H, Dam C, Takumi K, van der Giessen J (2014b) Increase in number of helminth species from Dutch red foxes over a 35-year period. Parasit Vectors 7:166-176

Gillis-Germitsch N, Muller S, Gori F, Schnyder M (2020) Capillaria boehmi (syn. Eucoleus boehmi): challenging treatment of a rarely diagnosed nasal nematode in dogs and high prevalence in Swiss foxes. Vet Parasitol 281:109103.

Gorski P, Zalewski A, Lakomy M (2006) Parasites of carnivorous mammals in Bialowieza Primeval Forest. Wiad Parazytol 52:49-53

Gottstein B, Stojkovic M, Vuitton DA, Millon L, Marcinkute A, Deplazes P (2015) Threat of alveolar echinococcosis to public health - a challenge for Europe. Trends Parasitol 31:407-412

Haemig PD, Lithner S, Sjostedt De Luna S, Lundkvist A, Waldenstrom J, Hansson L, Arneborn M, Olsen B (2008) Red fox and tick-borne encephalitis (TBE) in humans: can predators influence public health? Scand J Infect Dis 40:527-532
Hassell JM, Begon M, Ward MJ, Fevre EM (2017) Urbanization and disease emergence: dynamics at the wildlife-livestock-human interface. Trends Ecol Evol 32:55-67

Hsu MH, Wu WJ (2001) Off-host observations of mating and postmating behaviors in the cat flea (Siphonaptera: Pulicidae). J Med Entomol 38:352-360

Hurnikova Z, Dubinsky P (2009) Long-term survey on Trichinella prevalence in wildlife of Slovakia. Vet Parasitol 159:276-280

Ivanov VM, Semenova NN (2000) Parasitological consequences of animal introduction. Russ J Ecol 31:281-283

Kapel CM, Torgerson PR, Thompson RC, Deplazes P (2006) Reproductive potential of Echinococcus multilocularis in experimentally infected foxes, dogs, raccoon dogs and cats. Int $\mathrm{J}$ Parasitol 36:79-86

Karbowiak G, Szewczyk T, Werszko J (2016) Ectoparasites of carnivores in north-eastern Poland. Ann Parasitol 62:184

Kauhala K, Kowalczyk R (2011) Invasion of the raccoon dog Nyctereutes procyonoides in Europe: History of colonization, features behind its success, and threats to native fauna. Curr Zool 57:584-598

Khatchikian CE, Nadelman RB, Nowakowski J, Schwartz I, Levy MZ, Brisson D, Wormser GP (2015) Public health impact of strain specific immunity to Borrelia burgdorferi. BMC Infect Dis 15:1-7

Klaus C, Horugel U, Hoffmann B, Beer M (2013) Tick-borne encephalitis virus (TBEV) infection in horses: clinical and laboratory findings and epidemiological investigations. Vet Microbiol 163:368372

Kočišová A, Lazar P, Letková V, Čurlík J, Goldová MJVA (2006) Ectoparasitic species from red foxes (Vulpes vulpes) in East Slovakia. Vet Arh 76:59-63

Kornas S, Wierzbowska IA, Gorski P, Okarma H (2013) Occurrence of internal parasites in stone martens (Martes foina) from Cracow and suburbs. Ann Parasitol 59:203-205

Kornyushin V, Malega A (2011) The helminths of wild predatory mammals of Ukraine. Cestodes Vestn Zool 45:e-1-e-8

Laurimaa L, Suld K, Davison J, Moks E, Valdmann H, Saarma U (2016) Alien species and their zoonotic parasites in native and introduced ranges: the raccoon dog example. Vet Parasitol 219:24-33

Lledo L, Gimenez-Pardo C, Saz JV, Serrano JL (2015) Wild red foxes (Vulpes vulpes) as sentinels of parasitic diseases in the province of Soria, Northern Spain. Vector-Borne Zoonot 15:743-749

Lohr B, Muller I, Mai M, Norris DE, Schoffski O, Hunfeld KP (2015) Epidemiology and cost of hospital care for Lyme borreliosis in Germany: lessons from a health care utilization database analysis. Ticks Tick-Borne Dis 6:56-62

Macy RW, Berntzen AK (1971) Laboratory Guide to Parasitology. Charles G Thomas, Springfield, USA

Magurran AE, Henderson PA (2010) Temporal turnover and the maintenance of diversity in ecological assemblages. Philos Trans R Soc Lond Ser B Biol Sci 365:3611-3620

Manke KJ (1997) Parasitologische Untersuchungen an Rotfüchsen (Vulpes vulpes L.) aus den nördlichen Landesteilen SchleswigHolsteins. Tierärztliche Hochschule Hannover, Hanover, Germany.

McKinney ML (2008) Effects of urbanization on species richness: a review of plants and animals. Urban Ecosyst 11:161-176

MELUND (2019) Zur biologischen Vielfalt Jagd und Artenschutz Jahresbericht 2019. Ministry of Energy, Agriculture, the Environment, Nature and Digitalization; Schleswig-Holstein, Kiel.

Möhl K, Große K, Hamedy A, Wüste T, Kabelitz P, Lucker E (2009) Biology of Alaria spp. and human exposition risk to Alaria mesocercariae-a review. Parasitol Res 105:1-15

Murphy GE, Romanuk TN (2014) A meta-analysis of declines in local species richness from human disturbances. Ecol Evol 4:91-103

Murphy TM, O'Connell J, Berzano M, Dold C, Keegan JD, McCann A, Murphy D, Holden NM (2012) The prevalence and distribution of Alaria alata, a potential zoonotic parasite, in foxes in Ireland. Parasitol Res 111:283-290 
Nebel W (1996) Die Ergebnisse bisheriger Untersuchungen auf Echinococcus multilocularis in Schleswig-Holstein. In: Tackmann K, Janitschke K (eds) Zur epidemiologischen Situation des Echinococcus multilocularis - breitet sich eine gefährliche Parasitose in der Bundesrepublik Deutschland aus? RKI-Hefte 14. Robert-Koch-Institut, Berlin

Nijsse R, Mughini-Gras L, Wagenaar JA, Franssen F, Ploeger HW (2015) Environmental contamination with Toxocara eggs: a quantitative approach to estimate the relative contributions of dogs, cats and foxes, and to assess the efficacy of advised interventions in dogs. Parasit Vectors 8:397

OIE (2011) Immediate notification report. Report reference, Ref OIE: 10263, Report Date: 61/02/2011, Country: Sweden. Paris.

Oksanen A, Siles-Lucas M, Karamon J, Possenti A, Conraths FJ, Romig T, Wysocki P, Mannocci A, Mipatrini D, La Torre G, Boufana B, Casulli A (2016) The geographical distribution and prevalence of Echinococcus multilocularis in animals in the European Union and adjacent countries: a systematic review and meta-analysis. Parasit Vectors 9:519

Pawlowski Z, Eckert J, Vuitton DA, Ammann RW, Kern P, Craig PS, Dar KF, De Rosa F, Filice C, Gottstein B, Grimm F, Macpherson CNL, Sato N, Todorov T, Uchino J, von Sinner W, Wen H (2001) WHO/OIE manual on echinococcosis in humans and animals: a public health problem of global concern. In. World Organisation for Animal Health and World Health Organization, Paris.

Peus F (1938) Die Flöhe. Bau, Kennzeichen und Lebensweise, Hygienische Bedeutung und Bekämpfung der für den Menschen wichtigen Floharten. Hygienische Zoologie, vol. 5. Schöps, Leipzig.

Pfeffer M, Dobler G (2011) Tick-borne encephalitis virus in dogs-is this an issue? Parasit Vectors 4:59

Pfeiffer AS, Bockeler W, Lucius R (1989) Parasites of the domestic and wild animals of Schleswig-Holstein - parasites of the inner organs of the beech marten (Martes Foina). Z Jagdwiss 35:100-112

Piarroux M, Piarroux R, Knapp J, Bardonnet K, Dumortier J, Watelet J, Gerard A, Beytout J, Abergel A, Bresson-Hadni S, Gaudart J, Network FS (2013) Populations at risk for alveolar echinococcosis, France. Emerg Infect Dis 19:721-728

Riehn K, Hamedy A, Grosse K, Wuste T, Lucker E (2012) Alaria alata in wild boars (Sus scrofa, Linnaeus, 1758) in the eastern parts of Germany. Parasitol Res 111:1857-1861

RKI (2020) Infektionsepidemiologisches Jahrbuch Robert Koch-Institut. https://www.rki.de/DE/Content/Infekt/Jahrbuch/jahrbuch_node. html. Accessed 11.08.2020 2020

Rubinsky-Elefant G, Hirata CE, Yamamoto JH, Ferreira MU (2010) Human toxocariasis: diagnosis, worldwide seroprevalences and clinical expression of the systemic and ocular forms. Ann Trop Med Parasitol 104:3-23

Saeed I, Maddox-Hyttel C, Monrad J, Kapel CM (2006) Helminths of red foxes (Vulpes vulpes) in Denmark. Vet Parasitol 139:168-179

Said-Ali Z, Grenouillet F, Knapp J, Bresson-Hadni S, Vuitton DA, Raoul F, Richou C, Millon L, Giraudoux P, Network F (2013) Detecting nested clusters of human alveolar echinococcosis. Parasitology 140: $1693-1700$
Sato H, Inaba T, Ihama Y, Kamiya H (1999) Parasitological survey on wild carnivora in north-western Tohoku, Japan. J Vet Med Sci 61: 1023-1026

Schmidberger J, Kratzer W, Stark K, Gruner B, Grp EW (2018) Alveolar echinococcosis in Germany, 1992-2016. An update based on the newly established national AE database. Infection 46:197-206.

Schweiger A, Ammann RW, Candinas D, Clavien PA, Eckert J, Gottstein B, Halkic N, Muellhaupt B, Prinz BM, Reichen J, Tarr PE, Torgerson PR, Deplazes P (2007) Human alveolar echinococcosis after fox population increase, Switzerland. Emerg Infect Dis 13: 878-882

Shedrawy J, Henriksson M, Hergens MP, Askling HH (2018) Estimating costs and health outcomes of publicly funded tick-born encephalitis vaccination: a cost-effectiveness analysis. Vaccine 36:7659-7665

Shimalov VV, Shimalov VT (2002) Helminth fauna of the racoon dog (Nyctereutes procyonoides Gray, 1834) in Belorussian Polesie. Parasitol Res 88:944-945

Smith GC, Gangadharan B, Taylor Z, Laurenson MK, Bradshaw H, Hide G, Hughes JM, Dinkel A, Romig T, Craig PS (2003) Prevalence of zoonotic important parasites in the red fox (Vulpes vulpes) in Great Britain. Vet Parasitol 118:133-142

Soulsbury CD, Iossa G, Baker PJ, Cole NC, Funk SM, Harris S (2007) The impact of sarcoptic mange Sarcoptes scabiei on the British fox Vulpes vulpes population. Mammal Rev 37:278-296

Sutor A, Kauhala K, Ansorge H (2010) Diet of the raccoon dog Nyctereutes procyonoides - a canid with an opportunistic foraging strategy. Acta Theriol 55:165-176

Taylor MR, Keane CT, O'Connor P, Mulvihill E, Holland C (1988) The expanded spectrum of toxocaral disease. Lancet 1:692-695

Tomczuk K, Hirzmann J, Bauer C, Zięba P, Szczepaniak K, Studzińska M, Demkowska-Kutrzepa M, Roczeń-Karczmarz M (2019) Parasites as the etiology of paranal sinusitis in foxes. Ann Parasitol 65(suppl. 1):s43-s44

Vichova B, Bona M, Miterpakova M, Kraljik J, Cabanova V, Nemcikova G, Hurnikova Z, Oravec M (2018) Fleas and ticks of red foxes as vectors of canine bacterial and parasitic pathogens, in Slovakia, Central Europe. Vector-Borne Zoonot 18:611-619

Waldvogel A, Matile H, Wegmann C, Wyler R, Kunz C (1981) Tickborne encephalitis in the horse. Schweiz Arch Tierheilkd 123:227233

WHO (1984) Guidelines for surveillance, prevention and control of Echinococcosis/hydatidosis. In: Gemmell M, Matyas Z, Soulsby E (eds) Eckert J. WHO, Geneva

Zimmer IA, Fee SA, Spratt-Davison S, Hunter SJ, Boughtflower VD, Morgan CP, Hunt KR, Smith GC, Abernethy D, Howell M, Taylor MA (2009) Report of Trichinella spiralis in a red fox (Vulpes vulpes) in Northern Ireland. Vet Parasitol 159:300-303

Publisher's Note Springer Nature remains neutral with regard to jurisdictional claims in published maps and institutional affiliations. 